\title{
Exploring the prognosis of neuroblastoma in adolescents and adults: a case series and literature review
}

\author{
Qian-Ya JIN ${ }^{1,2}$, Shi-Bei DU11, Xiao-Jun YUAN ${ }^{1, *}$ \\ ${ }^{1}$ Department of Pediatric Hematology/Oncology, Xinhua Hospital Affiliated to Shanghai Jiao Tong University School of Medicine, Shanghai, \\ China; ${ }^{2}$ Department of Medicine, Quzhou College of Technology, Quzhou, Zhejiang, China
}

*Correspondence: yuanxiaojun@xinhuamed.com.cn

Received March 25, 2021 / Accepted December 5, 2021

\begin{abstract}
Neuroblastoma (NB) is one of the most common extracranial malignant solid tumors in childhood, and over $90 \%$ of NBs are diagnosed in children under the age of 10 years old. For patients between 14 and 18 years old or older than 18 years, due to the rarity of NB, few studies have been performed in this population. Defined "adolescent cases" as individuals in 14-18 years old and "adult cases" as older than 18 years old, we reported five NB cases of adolescents and adults in our hospital. 137 cases presented a review of published literature on this topic. Clinicopathological factors and treatment modalities used of the 142 patients were assessed for their prognostic value. Better outcomes were found in adolescent patients rather than adult patients $(\mathrm{p}=0.012)$. Patients diagnosed with neuroblastoma or ganglioneuroblastoma (nodular type) $(\mathrm{p}=0.006)$ and with distant metastasis $(\mathrm{p}<0.001)$ were characterized by poor outcomes. Distant metastasis was an independent adverse influencing factor for overall survival in adolescent and adult NB patients. Regarding treatment modalities, complete surgical resection was a significant factor improving the survival for such patients $(\mathrm{p}<0.001)$. For patients with distant metastasis, a significantly longer progression-free survival with chemotherapy than without chemotherapy $(\mathrm{p}=0.038)$, whereas chemotherapy did not show an advantage on patients with localized disease $(\mathrm{p}=0.039)$. The prognosis of NB in adolescent and adult patients was worse than that in children. These two groups also showed heterogeneity in clinical factors, genetic factors, and treatment tolerance. The rarity of adolescent and adult NB can lead to misdiagnosis and incorrect management. Further optimization of chemotherapy regimens and dosage for adolescent and adult NB patients is needed. The anti-GD2 immunotherapy may be an effective approach for treatment.
\end{abstract}

Key words: neuroblastoma, adolescent and adult, outcome, heterogeneity, treatment

Neuroblastoma (NB), an embryonic tumor originating from the sympathetic nervous system, is one of the most common extracranial malignant solid tumors in childhood and accounts for $7 \%$ of all childhood malignancies [1]. As a typical tumor of early childhood, over $90 \%$ of NB are diagnosed in children under the age of 10 years old [2]. The current risk classification of NB is based on the Children's Oncology Group (COG) guidelines [3]. It takes into account the patient's age at initial diagnosis, tumor stage, pathological characteristics, and genetic alterations, such as amplification of MYCN (encoding the transcription factor N-MYC). It is well known that older children suffer from more aggressive tumors and have a worse prognosis than younger children do. However, the prognosis of NB in adolescents and adults has not been sufficiently explored.

After the first case of adult NB was reported in 1905 [4], only over 400 cases of adolescent and adult NB had been reported. According to the review of the Surveillance, Epidemiology, and End Results (SEER) data which included cases coded as neuroblastoma and ganglioneuroblastoma diagnosed from 1973 to 2002, the 5-year overall survival (OS) rate was $85 \%$ for infants, whereas it was only $36 \%$ for adults [5]. It is evident that the overall outcome of the adult group is much worse than that of children with NB. Due to the rarity of $\mathrm{NB}$ in adolescents and adults, little is known about its natural history, and there are not yet systematic clinical trials aiming at this population. Therefore, in order to improve the prognosis of adolescent and adult patients with $\mathrm{NB}$, it is necessary to understand the characteristics of this special age compared to that of pediatric NB.

Against this backdrop, we defined "adolescents" as individuals 14-18 years old and "adults" as older than 18 years old. We reported five NB cases of adolescents and adults in our hospital and presented a review of published literature on 
this topic. The aim of this study is to explore the clinical outcomes of NB in adolescents and adults while taking into account various clinical features of the disease.

\section{Patients and methods}

Patients. This report described five patients with NB who were older than 14 at diagnosis and presented to the Xin Hua Hospital Affiliated to Shanghai Jiao Tong University School of Medicine. The diagnosis of NB was confirmed by histopathology in the Department of Pathology of our hospital. Disease status was assessed using computed tomography (CT), magnetic resonance imaging (MRI), or positron emission tomography-computed tomography (PET-CT). Bone marrow was evaluated by histochemical examination of biopsy specimens and aspirates. In addition, MYCN status and heterozygosity at $1 \mathrm{p}$ and $11 \mathrm{q}$ were assessed by fluorescence in situ hybridization analysis. Tumor staging was performed using the International Neuroblastoma Staging System and grouped based on COG classification. All patients were treated according to the Chinese Children Cancer Group-NB-2014 (CCCG-NB-2014) protocol [6]. The cut-off date for follow-up was conducted on December 31,2020 . The study procedures were approved by the Ethics Committee of Xin Hua Hospital Affiliated to Shanghai Jiao Tong University School of Medicine, and informed consent was obtained from all patients.

Literature review. A comprehensive literature search was performed in MEDLINE on PubMed (www.ncbi.nlm.nih. gov/pubmed) with the following terms: "adult" or "adolescent" or "young adult" combined with "neuroblastoma”. Only articles on patients diagnosed with neuroblastoma who were older than 14 years old were included. Articles were limited to full papers in the English language, and the search ended on December 31, 2020. Patients with intracranial primary NB were excluded from the study. Studies with no accurate clinical information or survival data were also excluded.

Statistical analysis. Statistical analyses were performed using the SPSS software version 23.0. OS and progressionfree survival (PFS) were analyzed using the Kaplan-Meier method. Multivariate analysis of OS was performed using Cox regression analysis. Statistical significance was set at p-value $<0.05$.

\section{Results}

Five adolescent and adult NB patients in our hospital. The characteristics and treatment details of the five patients in Xin Hua Hospital are shown in Table 1. The onset age of the patients ( 3 males and 2 females) ranged from 15 to 25 years old (median, 15 years old). Abdominal pain was the primary complaint in four patients, and fever was the first symptom in one patient. At the time of diagnosis, patients were grouped stage I $(n=1)$, stage III $(n=1)$, or stage IV $(n=3)$. Four patients were classified into the high-risk group, and one patient was divided into the low-risk group. The primary tumor site was the retroperitoneum in two patients and the adrenal gland in three cases. MYCN was normal in 3 of the 4 patients tested (Case 1 was not tested). Two patients had a loss of heterozygosity at $1 \mathrm{p}$, and one had a loss of heterozygosity at $11 \mathrm{q}$. All cases commenced therapy according to the CCCG-NB2014 protocol. Case 1 received radiation and chemotherapy, but she did not respond to chemotherapy and died after 28 months of follow-up. Case 2 was treated with upfront surgery followed by adjuvant chemotherapy and had a complete response. The treatment of case 3 was surgery combined with chemoradiotherapy and bone marrow transplantation. Case 4 received surgery and chemotherapy. Case 3 and 4

Table 1. Clinicopathological and therapeutic data of five cases of neuroblastoma managed in our hospital.

\begin{tabular}{|c|c|c|c|c|c|c|c|c|c|c|c|c|c|c|}
\hline $\begin{array}{l}\text { Case } \\
\text { NO. }\end{array}$ & $\begin{array}{c}\text { Age } \\
(y)\end{array}$ & Sex & $\begin{array}{c}\text { Initial } \\
\text { Symptoms }\end{array}$ & Histology & Stage & Risk & $\begin{array}{c}\text { Primary } \\
\text { sites }\end{array}$ & Metastases & MYCN & $1 p$ & $11 q$ & Therapy & $\begin{array}{l}\text { Out- } \\
\text { come }\end{array}$ & $\begin{array}{c}\text { Follow- } \\
\text { up (m) }\end{array}$ \\
\hline 1 & 20 & $\mathrm{~F}$ & Fever & $\begin{array}{l}\text { NB, } \\
\text { poorly dif- } \\
\text { ferentiated }\end{array}$ & IV & High & $\begin{array}{c}\text { Retro- } \\
\text { perito- } \\
\text { neal }\end{array}$ & $\begin{array}{l}\text { Bone, } \\
\text { Bone mor- } \\
\text { row }\end{array}$ & NA & NA & NA & $\begin{array}{c}\text { Chemo+ } \\
\text { RT }\end{array}$ & DOD & 28 \\
\hline 2 & 25 & $\mathrm{~F}$ & $\begin{array}{l}\text { Left side } \\
\text { abdominal } \\
\text { pain }\end{array}$ & $\begin{array}{l}\text { NB, } \\
\text { poorly dif- } \\
\text { ferentiated }\end{array}$ & I & Low & Adrenal & & $\mathrm{N}$ & $\mathrm{N}$ & NA & S+ Chemo & $\mathrm{ADF}$ & 19 \\
\hline 3 & 15 & M & $\begin{array}{c}\text { Low back pain } \\
\text { and abdomi- } \\
\text { nal pain }\end{array}$ & $\begin{array}{l}\mathrm{NB}, \\
\text { poorly dif- } \\
\text { ferentiated }\end{array}$ & IV & High & Adrenal & $\begin{array}{l}\text { Bone, } \\
\text { distant } \\
\text { lymph }\end{array}$ & Amp & Deleted & $\mathrm{N}$ & $\begin{array}{c}\text { Chemo+ } \\
\text { S+ RT+ } \\
\text { BM T }\end{array}$ & AWD & 15 \\
\hline 4 & 15 & $\mathrm{~F}$ & $\begin{array}{l}\text { Left upper } \\
\text { abdominal } \\
\text { pain }\end{array}$ & $\begin{array}{l}\mathrm{NB}, \\
\text { poorly dif- } \\
\text { ferentiated }\end{array}$ & IV & High & Adrenal & $\begin{array}{c}\text { Bone mor- } \\
\text { row, } \\
\text { distant } \\
\text { lymph }\end{array}$ & $\mathrm{N}$ & $\mathrm{N}$ & Deleted & Chemo + S & AWD & 8 \\
\hline 5 & 15 & M & $\begin{array}{l}\text { Left side } \\
\text { abdominal } \\
\text { pain }\end{array}$ & $\begin{array}{l}\text { NB, } \\
\text { poorly dif- } \\
\text { ferentiated }\end{array}$ & III & High & $\begin{array}{l}\text { Retro- } \\
\text { perito- } \\
\text { neal }\end{array}$ & & $\mathrm{N}$ & Deleted & $\mathrm{N}$ & Chemo & AWD & 2 \\
\hline
\end{tabular}

ADF: alive disease free; Amp: Amplified; AWD: alive with disease; BM T: bone marrow transplantation; Chemo: chemotherapy; DOD: die of disease; N: normal; NA: not available; NB: neuroblastoma; RT: radiotherapy; S: surgery 
were evaluated as partial remission and were still receiving chemotherapy as planned. Case 5 had currently received two courses of chemotherapy and remained on therapy.

Prognostic factors of adolescent and adult NB patients. Data of 142 adolescent and adult NB patients, including the 5 new cases (Table 1) and 137 cases from 68 literature reports [7-74], were extracted and reviewed carefully. The patient population comprised 62 males and 80 females. The age at diagnosis of 142 cases ranged from 15 to 86 years old, and the median age was 26.5 years old. The duration of followup varied dramatically (0.3-480 months), with a median follow-up of 21.5 months. Of the $142 \mathrm{NB}$ patients, there were 124 cases of NB, 3 of ganglioneuroblastoma, nodular type (GNBn), 13 of ganglioneuroblastoma (GNB), and 2 of ganglioneuroma (GN). At the time of diagnosis, 82 (57.8\%) patients had a primary tumor located in the abdomen, 2 (1.4\%) in the neck, $27(19.1 \%)$ in the thorax, $22(15.5 \%)$ in the pelvis, $7(4.9 \%)$ in the bones, and $2(1.4 \%)$ at other sites. Sixty-seven $(47.2 \%)$ patients had metastases at distant sites. Only six out of the 36 patients tested for MYCN status were amplification. Chromosome 1p deletions were reported in 4 out of 16 patients tested (Table 2).

We analyzed the relationship between various clinicopathological variables, including sex, age, pathological diagnosis, metastasis at diagnosis, MYCN status, loss of heterozygosity at $1 \mathrm{p}$, and prognosis. The results are presented in Table 3 . The patients who were diagnosed with NB and GNBn had poor clinical outcomes $(\mathrm{p}=0.006)$. Adolescent and adult NB patients with distant metastasis showed a significantly worse prognosis compared to those without metastasis $(\mathrm{p}<0.001)$. The prognosis was better for adolescents than for adults $(p=0.012)$. Finally, a multivariate analysis explored the correlation between certain known factors and their relationship with patient survival. Distant metastasis at diagnosis was an independent influencing factor for OS in adolescent and adult NB patients. The 5-year OS rate was only $15.7 \%$ for patients with distant metastasis compared to $64.4 \%$ for patients with localized disease (Figure 1).

Treatment and outcomes. One hundred and thirty-nine patients underwent therapeutic procedures and three refused any treatment. One hundred and two (71.8\%) cases were treated surgically to remove the tumor. Adjuvant therapy was administered in 115 (81.0\%) cases and included chemotherapy in $103(72.5 \%)$, radiotherapy in $59(41.5 \%)$, and both procedures in $47(33.1 \%)$ cases. Ten patients received a combination of bone marrow transplantation and conventional treatment. Three patients received targeted therapy, including two cases with GD2 antibody immunotherapy and one with crizotinib as a targeted therapy for Anaplastic Lymphoma Kinase (ALK). Ultimately, patients receiving anti-GD2 immunotherapy survived, whereas a patient with crizotinib died due to disease progression $[9,10,25]$. Notably, two patients only received palliative radiotherapy and both died (Table 4). The 5-year OS of NB patients who underwent different treatment modalities is shown in Table
Table 2. Characteristics of the enrolled 142 adolescent and adult NB patients.

\begin{tabular}{|c|c|c|}
\hline Characteristics & & $\mathbf{N}(\%)$ \\
\hline \multirow[t]{2}{*}{ Gender } & Male & $62(43.6)$ \\
\hline & Female & $80(56.4)$ \\
\hline \multirow[t]{4}{*}{ Age at diagnosis (y) } & $15-29$ & $82(57.8)$ \\
\hline & $30-44$ & $38(26.8)$ \\
\hline & $45-59$ & $13(9.1)$ \\
\hline & $\geq 60$ & $9(6.3)$ \\
\hline \multirow[t]{4}{*}{ Pathological subtype } & NB & $124(89.4)$ \\
\hline & GNBn & $3(2.1)$ \\
\hline & GNB & $13(9.2)$ \\
\hline & GN & $2(1.4)$ \\
\hline \multirow[t]{6}{*}{ Primary site } & Neck & $2(1.4)$ \\
\hline & Thorax & $27(19.1)$ \\
\hline & Abdomen & $82(57.8)$ \\
\hline & Pelvis & $22(15.5)$ \\
\hline & Bone & $7(4.9)$ \\
\hline & Others & $2(1.4)$ \\
\hline \multirow[t]{2}{*}{ Metastases } & Yes & $67(47.2)$ \\
\hline & No & $75(52.8)$ \\
\hline \multirow[t]{2}{*}{ MYCN status (36 tested) } & Normal & $30(21.2)$ \\
\hline & Amplified & $6(4.2)$ \\
\hline \multirow[t]{2}{*}{ Chromosome $1 \mathrm{p}$ ( 16 tested) } & Normal & $12(8.4)$ \\
\hline & Deleted & $4(2.8)$ \\
\hline
\end{tabular}

Abbreviations: NB-neuroblastoma; GNBn-ganglioneuroblastoma, nodular type; GNB-ganglioneuroblastoma; GN-ganglioneuroma

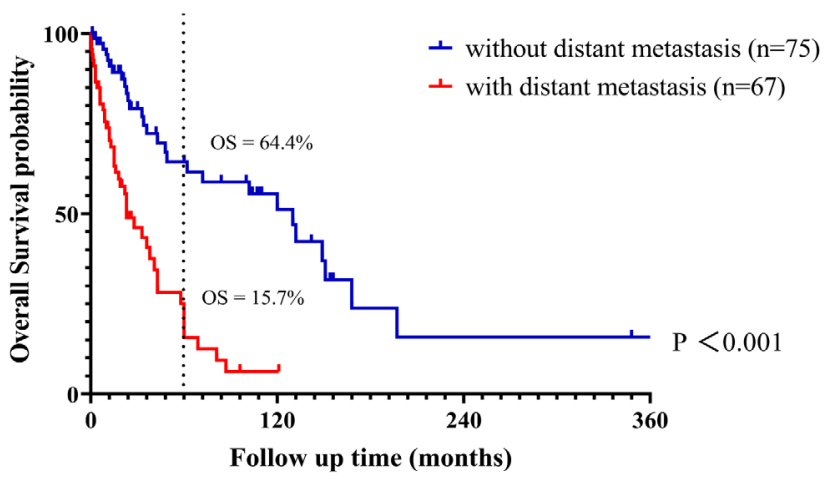

Figure 1. Kaplan-Meier analysis of the overall survival (OS) in adolescent and adult NB patients. The 5-year OS rate was only $15.7 \%$ for patients with distant metastasis compared to $\mathbf{6 4 . 4 \%}$ for patients with localized disease $(\mathrm{p}<0.001)$.

4. The OS rate of all patients was $41.6 \%$. Despite the survival rate differing by different treatments, patients who suffered surgery with radiotherapy were characterized by the highest survival rate.

Furthermore, we evaluated various therapeutic interventions that may influence NB prognosis. Surgical resection and chemotherapy are two major therapeutic modalities in clinical cancer treatment. As shown in Figure 2A, combined treatment with surgery and chemotherapy demonstrated superior 

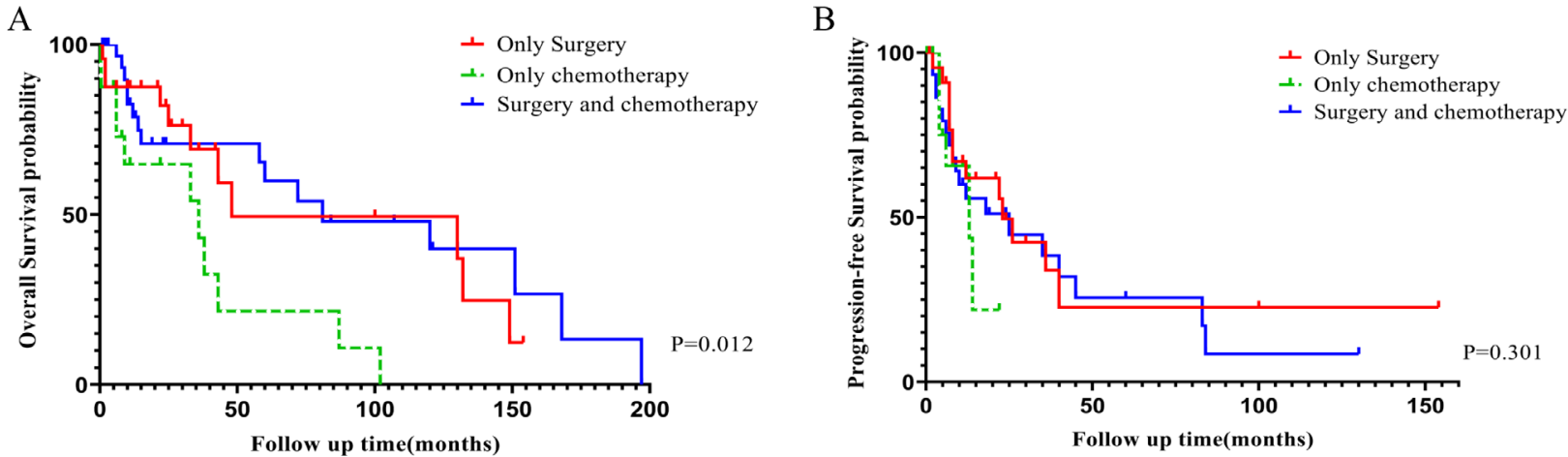

Figure 2. Effects of different treatment modalities on the prognosis of adolescent and adult NB patients. A) Kaplan-Meier estimated of OS classified by only surgery, only chemotherapy, and combination therapy with surgery and chemotherapy $(\mathrm{p}=0.012)$. B) Kaplan-Meier survival curves for patients treated with only surgery, only chemotherapy, and combination therapy with surgery and chemotherapy $(\mathrm{p}=0.301)$.

Table 3. Univariate and multivariate analyses of the overall survival in 142 NB patients.

\begin{tabular}{|c|c|c|c|c|c|c|}
\hline \multirow[t]{2}{*}{ Characteristics } & & & \multirow{2}{*}{$\begin{array}{c}\text { Univariate analysis } \\
\text { p-value }\end{array}$} & \multicolumn{3}{|c|}{ Multivariable analysis } \\
\hline & & & & p-value & HR & $95 \% \mathrm{CI}$ \\
\hline Gender & Male $(n=62)$ & Female $(n=80)$ & 0.310 & & & \\
\hline Age at diagnosis & $14-18$ years old $(n=16)$ & $\geq 18$ years old $(n=126)$ & 0.012 & 0.137 & 0.574 & $0.276-1.194$ \\
\hline Pathological subtype & NB, GNBn $(n=127)$ & GNB, GN $(n=15)$ & 0.006 & 0.054 & 0.363 & $0.130-1.017$ \\
\hline Metastases & Yes $(n=67)$ & No $(n=75)$ & 0.000 & 0.000 & 3.220 & $1.862-5.568$ \\
\hline MYCN status (36 tested) & Normal $(n=30)$ & Amplified $(n=6)$ & 0.132 & & & \\
\hline Chromosome $1 \mathrm{p}$ (16 tested) & Normal $(n=12)$ & Deleted $(n=4)$ & 0.660 & & & \\
\hline
\end{tabular}

Abbreviations: NB-neuroblastoma; GNBn-ganglioneuroblastoma, nodular type; GNB-ganglioneuroblastoma; GN-ganglioneuroma

Table 4. Survival of neuroblastoma patients who received different treatment modalities.

\begin{tabular}{lccc}
\hline Treatment modalities & $\begin{array}{c}\text { No. of } \\
\text { cases }\end{array}$ & Death & $\begin{array}{c}\text { 5-year } \\
\text { overall } \\
\text { survival } \\
\text { (\%) }\end{array}$ \\
\hline Without any therapy & 3 & 2 & 0.0 \\
Only surgery & 24 & 11 & 49.5 \\
Only chemotherapy & 16 & 11 & 21.6 \\
Only radiotherapy & 2 & 2 & 0.0 \\
$\begin{array}{l}\text { Surgery and chemotherapy } \\
\text { Surgery and radiotherapy }\end{array}$ & 34 & 16 & 60.1 \\
$\begin{array}{l}\text { Radiotherapy and chemotherapy } \\
\text { Surgery, chemotherapy, and radio- }\end{array}$ & 10 & 2 & 67.5 \\
therapy & 14 & 11 & 0.0 \\
$\begin{array}{l}\text { Combination treatment of conven- } \\
\text { tional treatment and bone marrow }\end{array}$ & 11 & 11 & 51.0 \\
transplantation & & 5 & 35.0 \\
$\begin{array}{l}\text { Combination treatment of convention- } \\
\text { al treatment and targeted therapy }\end{array}$ & 3 & 1 & 50.0 \\
Overall & 142 & 72 & 41.6 \\
\hline
\end{tabular}

therapeutic efficacy in OS to either chemotherapy alone or surgery alone $(p=0.012)$ whereas combined therapy did not show an advantage on PFS ( $p=0.301$, Figure $2 B)$. Moreover, the patients were grouped for further analysis. As shown in Figure $3 A$, patients who underwent surgery $(n=102)$ with or without adjuvant treatment had significantly longer survival rates than that of patients who were not operated on $(n=37$, median survival time: 72 months vs. 22 months, $\mathrm{p}<0.001$ ). No significance in survival was noted between those with or without chemotherapy (median survival time: 41 months vs. 130 months, $p=0.063$, Figure $3 \mathrm{~B}$ ). To assess the role of chemotherapy on the prognosis of adolescent and adult NB cases, patients were divided into two groups according to their metastatic status. For patients with metastatic disease at presentation, no differences were observed between patients with or without chemotherapy (median survival time of patients with chemotherapy vs. without chemotherapy: 28 months $[n=56]$ vs. 19 months $[n=9], p=0.162$, Figure 4A). A significantly longer PFS with chemotherapy than without chemotherapy in patients with distant metastasis (median PFS of patients with chemotherapy vs. without chemotherapy: 13 months $[\mathrm{n}=54]$ vs. 4 months $[\mathrm{n}=8], \mathrm{p}=0.038$, Figure 4B). However, the results for patients with a localized disease revealed an opposite trend. There was no statistical benefit in OS with chemotherapy (median survival time of patients with chemotherapy vs. without chemotherapy: 102 months [n=47] vs. 132 months [n=27], $\mathrm{p}=0.194$, Figure 4C). Unexpectedly, patients' concomitant chemotherapy group had significantly shorter PFS than patients without chemotherapy (median PFS of patients with chemotherapy vs. without chemotherapy: 12 months $[n=44]$ vs. 36 months $[n=26], p=0.039$, Figure 4D). 

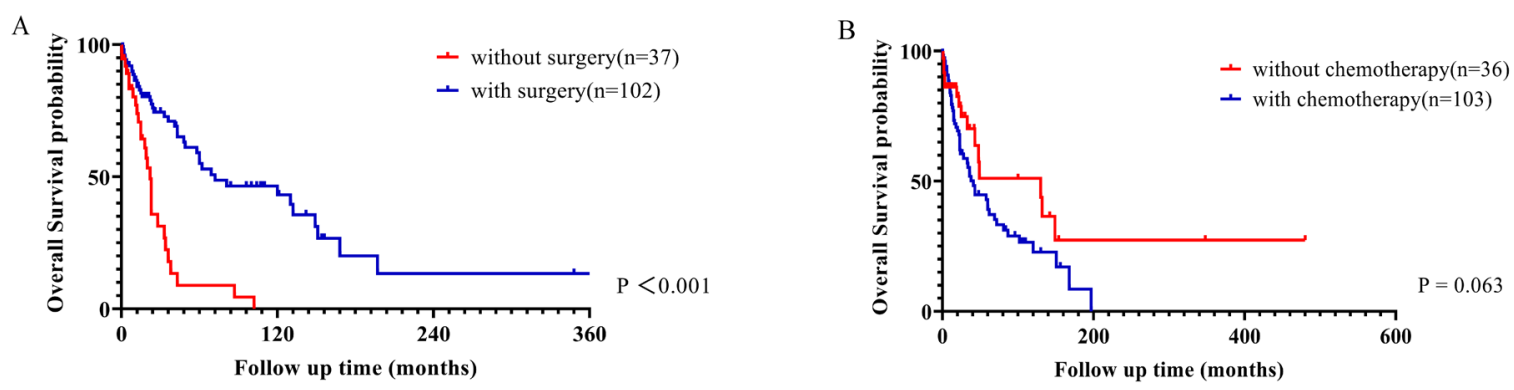

Figure 3. Effects of different treatment modalities on the prognosis of adolescent and adult NB patients. A) Patients who had a surgery demonstrated a longer median survival time than that of patients who were not operated on $(72$ months vs. 22 months, $p<0.001)$. B) There was no significant difference in the median survival time between patients with chemotherapy and those without chemotherapy $(41 \mathrm{months}$ vs. $130 \mathrm{months}, \mathrm{p}=0.063)$.

A

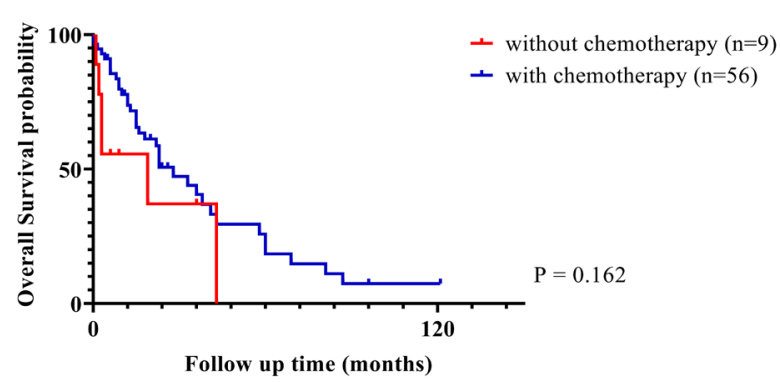

$\mathrm{C}$

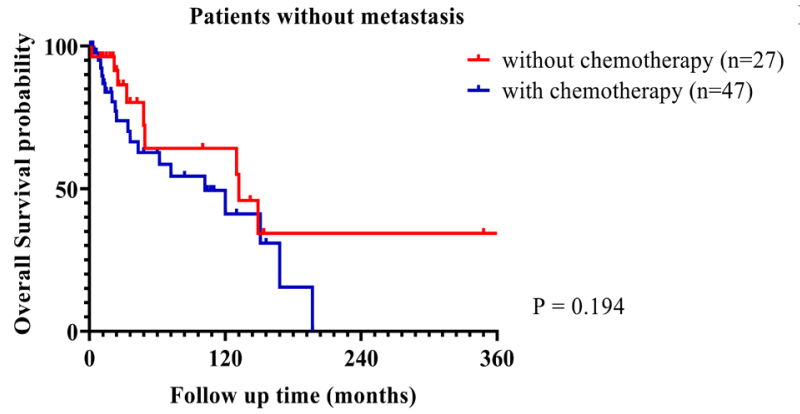

$\mathrm{B}$

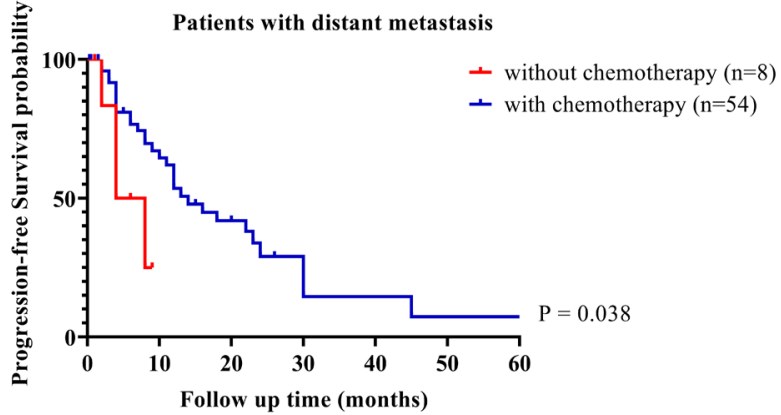

$\mathrm{D}$

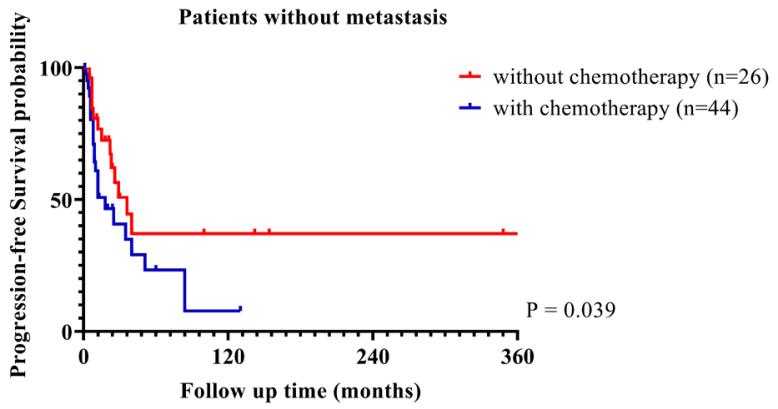

Figure 4. Prognostic relevance of chemotherapy and long-term survival in adolescents and adults according to NB metastasis. A) OS curves of patients with metastasis (median survival time of patients with chemotherapy vs. without chemotherapy: 28 months vs. 19 months, $p=0.162$ ). B) PFS curves of patients with metastasis (median PFS of patients with chemotherapy vs. without chemotherapy: 13 months vs. 4 months, $p=0.038$ ). C) OS curves of patients without metastasis (median survival time of patients with chemotherapy vs. without chemotherapy: 102 months vs. 132 months, $p=0.194$ ). $D$ ) PFS curves of patients without metastasis (median PFS of patients with chemotherapy vs. without chemotherapy: 12 months vs. 36 months, p=0.039),

\section{Discussion}

The occurrence of NB is closely related to the development of the neural crest, which mainly occurs in the adrenal glands and sympathetic ganglion. To the best of our knowledge, $\mathrm{NB}$ rarely occurs in adolescents and adults. Its incidence is approximately 1 case/100,000 children per year, whereas it is less than 0.3 cases/million people each year in adults [5, $75,76]$. Patients who are diagnosed with NB at over 20 years old account for only $6 \%$ of all NB cases [77]. For pediatric $\mathrm{NB}$, the 5-year OS in the low-risk group, intermediate-risk group, and high-risk group is over 90\%, 60-85\%, and less than 50\%, respectively [2]. However, in adolescent and adult NB patients, the 5-year OS rate is only $15.7 \%$ for those with distant metastasis compared to $64.4 \%$ for cases with localized disease. The survival rate of adolescent and adult NB patients is significantly lower than that of the pediatric NB population. Further study is needed to reveal some contributors to such differences in prognosis.

Compared with pediatric NB, adult NB is characterized by large clinical heterogeneity and tolerance to treatment. The signs and symptoms of NB are highly variable and depend 
on the site of the primary tumor as well as the presence or absence of metastatic disease. The locations of NB in adolescents and adults are similar to those in pediatric patients, with the abdomen being the most common area of NB occurrence. However, owing to its rarity, $16 \%$ of adult NB cases are misdiagnosed initially and are managed incorrectly [78]. In fact, 25 of the 142 patients were misdiagnosed before operation due to non-specific signs and symptoms. In cases with a lack of pathological evidence, patients were commonly misdiagnosed with pheochromocytoma. Small round blue cells and rosette-forming cells are typical manifestations of NB, but it should be differentiated from lymphoma and primitive neuroectodermal tumor, which report similar clinicopathological features [72]. The interval between the onset of symptoms and clinical diagnosis was longer in adolescents and adults than that of children. In pediatric NB, approximately $38 \%$ of cases were classified as stage IV disease [79]. Similar to previous studies that reported high rates of metastasis, of the 142 adolescent and adult NB patients, we found that approximately $47.2 \%$ presented with metastatic disease, and correlated with poor prognosis. This may be associated with an indolent clinical course of the disease in adolescent and adult population [80].

Elevated levels of serum neuron-specific enolase (NSE) and urine catecholamine metabolites (such as vanillylmandelic acid and homovanillic acid) are seen in $90 \%$ of pediatric $\mathrm{NB}$ cases and are used as tumor biomarkers for children with NB; however, they are rarely elevated in adolescents and adults [73]. Among the analyzed cases, these biomarkers were abnormal only in 19 out of 31 patients, accounting for difficulties in diagnosis. Compared with 20-25\% prevalence of MYCN amplification in children, which is associated with an aggressive phenotype, only $9 \%$ of adolescent and adult NB patients have been reported to have MYCN amplification [81]. Whereas, $16.7 \%$ of cases had MYCN amplification in our case series. We speculate that this may be due to the absence of MYCN status in most literature reviewed. Conversely, ALK and ATRX Chromatin Remodeler (ATRX) mutations are far more common in adults, which suggests that the drivers of tumorigenesis in adult NB maybe differ from those in children, and may be related to slower growth phenotypes [78, 82]. Compared with children, NB diagnosis in adults is more dependent on the pathological evidence. In addition, tumor cells often express CD56, chromogranin A, synaptophysin, neurofilament, and NSE. Recently, paired like homeobox 2B (PHOX2B), a master regulator of neural crest development, has been detected in NB as a new, sensitive, and specific marker [83].

The rarity of NB in adults has resulted in a lack of systematic clinical trials for chemotherapeutic agents or targeted therapy aiming at this population. Therefore, the treatment of adult patients with NB generally depends on the regimens used for pediatric NB. Comprehensive treatment is an important means of increasing the survival of children with NB [80]. Based on our findings, compared with surgery or chemotherapy only, the long-term survival had improved significantly by combination therapies but no longer progression-free survival for adolescent and adult NB patients. Results also showed that complete surgical resection was a significant factor for improving the survival of this population whereas chemotherapy did not improve the long-term prognosis. This may be related to the fact that adults have a poorer tolerance to chemotherapy compared to that of children [80]. Side effects of chemotherapy, including hair loss, vomiting, and myelosuppression, were observed in five patients treated in our institution. Two patients were insensitive to chemotherapy. We found that 55 of 73 cases reported in reviewed literature also received chemotherapy. It is worth mentioning that 5 of 55 patients $(9.1 \%)$ died from chemotherapy-related complications. This suggests that more effective regimens of chemotherapy for adolescent and adult NB cases should be considered to overcome limitations. When the analyses were performed in two groups according to metastasis, there was a trend toward a worse prognosis in patients without metastasis who received chemotherapy. For adolescent and adult NB patients, combination treatment was more effective than individual treatments. Early complete surgical resection combined with appropriate chemotherapy is recommended to improve the outcome in this population, radical surgical management is particularly important to reduce recurrence. Chemotherapy plays a key role in the treatment of children with NB, but the current regimen may not be suitable for adolescents and adults. The details of the chemotherapy regimens and doses will need to be investigated further.

GD2, a disialoganglioside, is a surface antigen overexpressed on NB cells surface but limited to neurons, melanocytes, and peripheral pain fibers in normal tissue. GD2 facilitates the attachment of tumor cells to the extracellular matrix and persists on NB cell membrane post-therapy [84]. Furthermore, GD2 is associated with proliferation, invasion, and motility. These properties make it a suitable target for immunotherapy. With the development of immunotherapy, clinical trials with anti-GD2 monoclonal Abs (mAb) have shown promising results in pediatric NB. Immunotherapy with anti-GD2 mAb was shown in a Children's Oncology Group phase III randomized clinical trial to have superior event-free survival ( $2 \mathrm{y}$-EFS, $66 \pm 5 \%$ vs. $46 \pm 5 \%)$ and overall survival ( $2 y-O S, 86 \pm 4 \%$ vs. $75 \pm 5 \%$ ) when compared with standard therapy with isotretinoin alone [85]. In 2015, the Food Drug Administration approved the use of dinutuximab, an anti-GD2 $\mathrm{mAb}$, and incorporated it into the standard of care therapy for patients with high-risk NB [86]. For patients with refractory or relapsed NB, the use of anti-GD2 immunotherapy has led to further improvement in OS and EFS after conventional therapy [80]. Adolescent and adult NB is an insidious onset with a high rate of metastasis. Due to its rarity, the diagnosis is often difficult for this population, and easy to delay treatment. Older age onset is also a high-risk factor for NB, and nearly half of those patients 
are at an advanced stage at the time of diagnosis [80]. So, it may be speculated that these patients may potentially benefit from anti-GD2 immunotherapy therapy. There is limited evidence confirming this conjecture. At the Memorial Sloan Kettering Cancer Center, 5 out of 7 adult NB patients treated with anti-GD2 immunotherapy had a complete response and showed good tolerance to the treatment [78]. In the study, we found that two cases with GD2 antibody immunotherapy all survived. Given the positive outcomes of immunotherapy in pediatric NB, there is a reason to believe that anti-GD2 immunotherapy is promising for the treatment of $\mathrm{NB}$ in adolescent and adult NB. Further studies are required to confirm these observations.

Previous studies have shown that adult NB has a protracted course, referred to as indolent or chronic NB [87]. The prognosis is worse in adolescent and adult patients with NB than in children. We find that distant metastasis is an independent influencing factor for the outcome of adolescent and adult patients with NB. NB is characterized by a variety of genetic abnormalities, which may explain different clinical outcomes between children and adults. Surgical resection remains the mainstay in NB treatment. Further exploration of chemotherapy regimens and dosage for adolescent and adult patients with NB is necessary. Anti-GD2 immunotherapy may be emerged as an effective approach to improve clinical outcomes.

Acknowledgments: This work was supported by the Medical Science Project of the Shanghai Science and Technology Commission [grant number 16411962500].

\section{References}

[1] ROBISON LL, ARMSTRONG GT, BOICE JD, CHOW EJ, DAVIES SM et al. The Childhood Cancer Survivor Study: a National Cancer Institute-supported resource for outcome and intervention research. J Clin Oncol 2009; 27: 2308-2318. https://doi.org/10.1200/JCO.2009.22.3339

[2] NAKAGAWARA A, LI Y, IZUMI H, MURAMORI K, INADA H et al. Neuroblastoma. Jpn J Clin Oncol 2018; 48: 214-241. https://doi.org/10.1093/jjco/hyx176

[3] STROTHER DR, LONDON WB, SCHMIDT ML, BRODEUR GM, SHIMADA $H$ et al. Outcome after surgery alone or with restricted use of chemotherapy for patients with lowrisk neuroblastoma: results of Children's Oncology Group study P9641. J Clin Oncol 2012; 30: 1842-1848. https://doi. org/10.1200/JCO.2011.37.9990

[4] WRIGHT JH. Neurocytoma or neuroblastoma, a kind of tumor not generally recognized. J Exp Med 1910; 12: 556-561. https://doi.org/10.1084/jem.12.4.556

[5] ESIASHVILI N, GOODMAN M, WARD K, MARCUS RB JR, JOHNSTONE PA. Neuroblastoma in adults: Incidence and survival analysis based on SEER data. Pediatr Blood Cancer 2007; 49: 41-46. https://doi.org/10.1002/pbc.20859
[6] ZHAO Q, WU YM. Expert consensus on diagnosis and treatment of neuroblastoma in children. Chin J Pediatr Surg 2015; 36: 3-7.

[7] THAPA BB, YADAV S, PANT S, RAJKARNIKAR P, MANDAL P. Surgical Management of Giant L2 Adrenal Neuroblastoma in Adult Male. Case Rep Urol 2020; 2020: 8890223. https://doi.org/10.1155/2020/8890223

[8] VIECELI T, TAVARES ALJ, DE MORAES RP, FAULHABER GAM. Metastatic adult neuroblastoma with spontaneous tumor lysis syndrome. Autops Case Rep 2020; 10: e2020181. https://doi.org/10.4322/acr.2020.181

[9] GARROVILLO K, GARRETT J, BOLLIN K, NASRATY F, SIKAND H. Dinutuximab i n adult-onset chemotherapy refractory high-risk neuroblastoma. J Oncol Pharm Pract 2020; 26: 2058-2065. https://doi.org/10.1177/1078155220918920

[10] MATSUNO R, AKIYAMA K, TOYAMA D, IKEDA H, YAMAMOTO S. Adolescent pulmonary metastatic neuroblastoma with ALK rearrangement: A case report. Pediatr Int 2020; 62: 507-509. https://doi.org/10.1111/ped.14117

[11] BUKHARI N, HARFOUCH B, ALOTAIBI MS, AL-HARBI $\mathrm{H}$, CHAMDINE O. Immediate Response to Chemotherapy in an Adult Neuroblastoma Patient Presenting with Cord Compression. Case Rep Neurol Med 2020; 2020: 6401497. https://doi.org/10.1155/2020/6401497

[12] SEKIGUCHI N, NOGUCHI T, FUKUSHIMA T, KOBAYASHI T, OZAWA T et al. Posterior mediastinal ganglioneuroblastoma in an adolescent: A case report and review. Thorac Cancer 2020; 11: 451-455. https://doi.org/10.1111/17597714.13277

[13] ZHANG H, FENG Z. Adrenal neuroblastoma in an elderly adult: a case report and review of the literature. J Med Case Rep 2019; 13: 284. https://doi.org/10.1186/s13256-019-2204-7

[14] CHAI L, CIULLO S, PRASAD R. Case report of severe psychiatric sequelae in a 16 -year-old female following resection of a purely dopamine-secreting ganglioneuroma. Int J Surg Case Rep 2019; 61: 263-266. https://doi.org/10.1016/j. ijscr.2019.07.028

[15] TAN YB, LI JF, LI WS, YANG RL. Primary thoracic neuroblastoma in an adult: A rare case report. Medicine (Baltimore) 2019; 98: e16564. https://doi.org/10.1097/ MD.0000000000016564

[16] MARTINEZ-CIARPAGLINI C, MACHADO I, YOSHIDA A, NIETO G, BERBEGALL AP et al. Extra-Adrenal Adult Neuroblastoma With Aberrant Germ Cell Marker Expression: Maturation After Chemotherapy as an Important Clue to a Challenging Diagnosis. Int J Surg Pathol 2019; 27: 568573. https://doi.org/10.1177/1066896919835945

[17] WU XL, DAI YJ, SUN GY, WANG LK, HAN L et al. Adult neuroblastoma in the retroperitoneum: A case report. Medicine (Baltimore) 2018; 97: e13750. https://doi.org/10.1097/ MD.0000000000013750

[18] NAEEM M, MALUF H, BAKER JC, JENNINGS JW. Primary osseous sacral neuroblastoma in an adult. Skeletal Radiol 2019; 48: 985-988. https://doi.org/10.1007/s00256-0183081-7 
[19 HUANG MD, HSU LS, CHUANG HC, LIN WY, LIN WH et al. Adult renal neuroblastoma: A case report and literature review. Medicine (Baltimore) 2018; 97: e0345. https://doi. org/10.1097/MD.0000000000010345

[20] ADACHI T, YOKOYAMA M, FUJII Y, KINOWAKI Y, KIRIMURA $S$ et al. Neuroblastic tumors in young adults as a sequela of malignant neuroblastoma: report of two cases. Abdom Radiol (NY) 2018; 43: 1531-1534. https://doi. org/10.1007/s00261-018-1586-0

[21] YANIK F, KARAMUSTAFAOGLU YA, YORUK Y. A rare mediastinal occurrence of neuroblastoma in an adult: case report. Sao Paulo Med J 2019; 137: 104-106. https://doi. org/10.1590/1516-3180.2017.0160140617

[22] HE Y, YAO M, ZHANG X, SUN P, GAO H. A very rare adult case of cervical neuroblastoma. Int J Clin Exp Pathol 2017; 10: 8746-8750.

[23] GODKHINDI VM, BASADE MM, KHAN K, THORAT K. Adult Neuroblastoma-Case Report and Literature Review. J Clin Diagn Res 2016; 10: ED01-ED02. https://doi. org/10.7860/JCDR/2016/20237.9080

[24] ÖDEK Ç, KENDIRLI T, PEKPAK E, YAMAN A, ADAKL1AKSOY B et al. An unusual case of neuroblastoma: a 17-yearold adolescent presented with bilateral diffuse lung metastasis at initial diagnosis. Turk J Pediatr 2016; 58: 86-89. https:// doi.org/10.24953/turkjped.2016.01.012

[25] MADEO A, GARAVENTA A, SEMENTA AR, SUFFIA C, DI ROCCO M. The unusual association between Neuroblastoma and Gaucher Disease: Case report and review of the literature. Blood Cells Mol Dis 2018; 68: 106-108. https:// doi.org/10.1016/j.bcmd.2016.11.011

[26] KUROKAWA S, MIZUNO K, NAKANE A, MORITOKI Y, NISHIO $\mathrm{H}$ et al. Adrenal Neuroblastoma in an Adult: Effect of Radiotherapy on Local Progression after Surgical Removal. Case Rep Urol 2016; 2016: 2657632. https://doi. org/10.1155/2016/2657632

[27] LIU QL, LIANG QL, OU WT, LI ZY, ZHANG XN. Surgical resection and post-operative radiotherapy in an adult renal neuroblastoma patient with multiple bone and joint metastases: A case report. Oncol Lett 2015; 9: 2591-2594. https:// doi.org/10.3892/ol.2015.3109

[28] STEVENS PL, JOHNSON DB, THOMPSON MA, KEEDY VL, FRANGOUL HA et al. Adult neuroblastoma complicated by increased intracranial pressure: a case report and review of the literature. Case Rep Oncol Med 2014; 2014: 341980. https://doi.org/10.1155/2014/341980

[29] ROGOWITZ E, BABIKER HM, KANAAN M, MILLIUS RA, RINGENBERG QS et al. Neuroblastoma of the elderly, an oncologist's nightmare: case presentation, literature review and SEER database analysis. Exp Hematol Oncol 2014; 3: 20 .

[30] KARANGELIS D, NIKOLAIDIS N, ROUBELAKIS A, WEEDEN DF. Giant thoracoabdominal ganglioneuroblastoma in a 17-year-old patient. Asian Cardiovasc Thorac Ann 2014; 22: 739-741. https://doi. org/10.1177/0218492313490410
[31] KOUMARIANOU A, OIKONOMOPOULOU P, BAKA M, VLACHODIMITROPOULOS D, ARGENTOS S et al. Implications of the Incidental Finding of a MYCN Amplified Adrenal Tumor: A Case Report and Update of a Pediatric Disease Diagnosed in Adults. Case Rep Oncol Med 2013; 2013: 393128. https://doi.org/10.1155/2013/393128

[32] GUPTA P, MAITI A, AICH RK, DEB AR. Adrenal neuroblastoma in an adult. J Cancer Res Ther 2013; 9: 96-98. https://doi.org/10.4103/0973-1482.110389

[33] SMITH L, MINTER S, O'BRIEN P, KRAVEKA JM, MEDINA AM et al. Neuroblastoma in an adult: case presentation and literature review. Ann Clin Lab Sci 2013; 43: 81-84.

[34] UEDA Y, OMASA M, TAKI T, OKABE R, CHO H et al. Thymic Neuroblastoma within a Thymic Cyst in an Adult. Case Rep Oncol 2012; 5: 459-463. https://doi. org/10.1159/000342357

[35] BAYRAK O, SECKINER I, ERTURHAN S, AYDIN A, YAGCI F. Adult intrarenal neuroblastoma presenting as renal cell carcinoma. Can Urol Assoc J 2012; 6: E144-146. https://doi. org/10.5489/cuaj.11119

[36] SELCUKBIRICIK F, TURAL D, ESATOGLU N, KOCAK S, MANDEL NM. A very rare adult case with neuroblastoma. Case Rep Oncol 2011; 4: 481-486. https://doi. org/10.1159/000332761

[37 ABDOU AG, ASAAD NY, ELKASED A, SAID H, DAWOUD M. Adult pancreatic neuroblastoma, an unusual site and fatal outcome. Pathol Oncol Res 2012; 18: 239-243. https://doi. org/10.1007/s12253-011-9434-3

[38] THEN C, EBELT K, LANGER A, MAYR D, SCHMIDMAIER R et al. Neuroblastoma in a 55-year-old patient: a case report. Case Rep Oncol 2010; 3: 458-462. https://doi. org/10.1159/000322863

[39] OHTAKI Y, ISHII G, HASEGAWA T, NAGAI K. Adult neuroblastoma arising in the superior mediastinum. Interact Cardiovasc Thorac Surg 2011; 13: 220-222. https://doi. org/10.1510/icvts.2010.262204

[40] MIRANDA SOARES PB, QUIRINO FILHO S, PEREIRA DESW, FERRETI BONAN PR, MARTELLI-JÚNIOR H. Neuroblastoma in an adult: case report. Rev Med Chil 2010; 138: 1131-1134.

[41] JOST G, FRANK S, FISCHER N, TAUB E, MARIANI L. An epidural neuroblastoma causing spinal cord compression in a 67-year-old woman. Rare Tumors 2010; 2: e27. https://doi. org/10.4081/rt.2010.e27

[42] VENAT-BOUVET L, LE BRUN-LY V, MARTIN J, GASNIER O, FALKOWSKY $S$ et al. Long-Term Survival in Adult Neuroblastoma with Multiple Recurrences. Case Rep Oncol 2010; 3: 45-48. https://doi.org/10.1159/000286142

[43] JARIUS S, ARNOLD S, LINKE R, NOACHTAR S, SCHLEMMER $\mathrm{M}$ et al. Long term survival in anti-Hu associated adult neuroblastoma. J Neurol Sci 2009; 284: 205-208. https://doi.org/10.1016/j.jns.2009.04.007

[44] NZEGWU MA, AGHAJI A. Neuroblastoma occurring in a 38-year old Nigerian man: a rare finding. Rare Tumors 2009; 1: e15. https://doi.org/10.4081/rt.2009.e15 
[45] REFAAT MM, IDRISS SZ, BLASZKOWSKY LS. Case report: an unusual case of adrenal neuroblastoma in pregnancy. Oncologist 2008; 13: 152-156. https://doi.org/10.1634/theoncologist.2006-0180

[46] GENC H, HACIYANLI M, HACIYANLI SG, GELAL F, AVCI UCARSOY A et al. An adult adrenal neuroblastoma: a case report. Acta Chir Belg 2005; 105: 673-676. https://doi. org/10.1080/00015458.2005.11679803

[47] SCHALK E, MOHREN M, KOENIGSMANN M, BUHTZ $\mathrm{P}$, FRANKE A et al. Metastatic adrenal neuroblastoma in an adult. Onkologie 2005; 28: 353-355. https://doi. org/10.1159/000085526

[48] MCLEAN TW, ISKANDAR SS, SHIMADA H, HALL MC. Neuroblastoma in an adult. Urology 2004; 64: 1232. https:// doi.org/10.1016/j.urology.2004.06.031

[49] GENC FA, AKSOY M, KAPRAN Y, TUNCA F, TANAKOL $\mathrm{R}$ et al. Adrenal neuroblastoma in an adult: report of a case. Surg Today 2003; 33: 879-881. https://doi.org/10.1007/ s00595-003-2622-3

[50] SHIMIZU M, SHIMIZU T, ADACHI T, NISHIUCHI M, KANZAKI $\mathrm{M}$ et al. Long-term survival in adult mediastinal neuroblastoma. Jpn J Thorac Cardiovasc Surg 2003; 51: 326-329. https://doi.org/10.1007/BF02719388

[51] KAWAKAMI M, KODA M, MATSUNAGA N, KISHIMOTO Y, SHABANA M et al. Adult-type neuroblastoma originated in retroperitoneum beginning with obstructive jaundice. Clin Imaging 2001; 25: 284-287. https://doi.org/10.1016/ s0899-7071(01)00288-1

[52] YAMAMOTO R, TADA H, KISHI A, TOJO T, ASADA H et al. Neuroblastoma resection in an adult with a 10-year history of chest-mass shadow. Jpn J Thorac Cardiovasc Surg 2000; 48: 809-811. https://doi.org/10.1007/BF03218256

[53] CUSTODIO CM, SEMELKA RC, BALCI NC, MITCHELL KM, FREEMAN JA. Adrenal neuroblastoma in an adult with tumor thrombus in the inferior vena cava. J Magn Reson Imaging 1999; 9: 621-623. https://doi.org/10.1002/(sici)15222586(199904)9:4<621::aid-jmri17>3.0.co;2-2

[54] HIROKAWA S, YAMASHITA I, KUROKI Y, YAMASHITA $\mathrm{Y}$, FUJIMAKI $\mathrm{M}$ et al. Neuroblastoma in an adult with a high serum level of carbohydrate antigen, CA125: report of a case. Surg Today 1998; 28: 349-354. https://doi.org/10.1007/ s005950050139

[55] NAGASHIMA Y, MIYAGI Y, TANAKA Y, MIYASHITA $\mathrm{M}$, SHIGEMATSU S et al. Adult Gang lioneuroblastoma of the Anterior Mediastinum. Pathology - Research and Practice 1997; 193: 727-732. https://doi.org/10.1016/S03440338(97)80034-9

[56] MOODY AM, NORMAN AR, TAIT D. Paediatric tumours in the adult population: the experience of the Royal Marsden Hospital 1974-1990. Med Pediatr Oncol 1996; 26: 153-159. https://doi.org/10.1002/(SICI)1096911X(199603)26:3<153::AID-MPO2>3.0.CO;2-J

[57] OHASHI K, SAWADA H, KANAIZUMI T, NAKANO H, OKAMOTO $\mathrm{S}$ et al. Adult neuroblastoma in pregnancy: report of a case. Surg Today 1993; 23: 742-746. https://doi. org/10.1007/BF00311716
[58] ROSSITTI SL, DE MATOS PS, BALBO RJ, ZUIANI AR THOMAZ IR. Adult peripheral neuroblastoma. Arq Neuropsiquiatr 1991; 49: 357-361. https://doi.org/10.1590/ s0004-282x1991000300023

[59] URIOS JI, GARCERAN LR, ROSELL TV. Neuroblastoma in an adult causing spinal cord compression: report of a case and review of the literature. Paraplegia 1989; 27: 394-401. https://doi.org/10.1038/sc.1989.62

[60] KRIKKE AP, VAN DER JAGT EJ. Adult neuroblastoma: a report of two cases. Rofo 1989; 150: 138-141. https://doi. org/10.1055/s-2008-1046992

[61] HOOVER EL, HSU HK, DRESSLER C, FANI K, WEBB H et al. Neuroblastoma: a rare primary intrathoracic neurogenic tumor in adults. Tex Heart Inst J 1988; 15: 107-112.

[62] KENNEDY MJ, EUSTACE P, O'BRIAIN DS, DALY PA. Paraneoplastic papilloedema in neuroblastoma. Postgrad Med J 1987; 63: 873-876. https://doi.org/10.1136/pgmj.63.744.873

[63] MACKAY B, ORDÓÑEZ NG. Adult neuroblastoma of bone: a case report. Ultrastruct Pathol 1987; 11: 455-464. https:// doi.org/10.3109/01913128709048440

[64] KAYE JA, WARHOL MJ, KRETSCHMAR C, LANDSBERG L, FREI E 3RD. Neuroblastoma in adults. Three case reports and a review of the literature. Cancer 1986; 58: 1149-1157. https://doi.org/10.1002/10970142(19860901)58:5<1149::aid-cncr2820580529>3.0.co;2-3

[65] ALLAN SG, CORNBLEET MA, CARMICHAEL J, ARNOTT SJ, SMYTH JF. Adult neuroblastoma. Report of three cases and review of the literature. Cancer 1986; 57: 2419-2421. https:// doi.org/10.1002/1097-0142(19860615)57:12<2419::aidcncr2820571228>3.0.co;2-v

[66] GRUBB BP, THANT M. Neuroblastoma in an adult. South Med J 1984; 77: 1180-1182. https://doi. org/10.1097/00007611-198409000-00034

[67] LOPEZ R, KARAKOUSIS C, RAO U. Treatment of adult neuroblastoma. Cancer 1980; 45: 840-844. https:// doi.org/10.1002/1097-0142(19800301)45:5<840::aidcncr2820450503>3.0.co;2-z

[68] BAUMGARTNER GC, GAETA J, WAJSMAN Z, MERRIN C. Neuroblastoma presenting as renal cell carcinoma in an adult. Urology 1975; 6: 376-378. https://doi. org/10.1016/0090-4295(75)90774-8

[69] HALE JE. A case of neuroblastoma in an adult with raised catecholamines. Br J Surg 1970; 57: 551-553. https://doi. org/10.1002/bjs.1800570720

[70] JREBI NY, IQBAL CW, JOLIAT GR, SEBO TJ, FARLEY DR. Review of our experience with neuroblastoma and ganglioneuroblastoma in adults. World J Surg 2014; 38: 2871-2874. https://doi.org/10.1007/s00268-014-2682-0

[71] SORRENTINO S, GIGLIOTTI AR, SEMENTA AR, MORSELLINO V, CONTE $M$ et al. Neuroblastoma in the adult: the Italian experience with 21 patients. J Pediatr Hematol Oncol 2014; 36: e499-505. https://doi.org/10.1097/ MPH.0000000000000144

[72] HASEGAWA T, HIROSE T, AYALA AG, ITO S, TOMARU $\mathrm{U}$ et al. Adult neuroblastoma of the retroperitoneum and abdomen: clinicopathologic distinction from primitive neuroectodermal tumor. Am J Surg Pathol 2001; 25: 918-924. https://doi.org/10.1097/00000478-200107000-00010 
[73] FRANKS LM, BOLLEN A, SEEGER RC, STRAM DO, MATTHAY KK. Neuroblastoma in adults and adolescents: an indolent course with poor survival. Cancer 1997; 79: 2028-2035. https://doi.org/10.1002/(sici)10970142(19970515)79:10<2028::aid-cncr26>3.0.co;2-y

[74] DOSIK GM, RODRIGUEZ V, BENJAMIN RS, BODEY GP. Neuroblastomain the adult: effective combination chemotherapy. Cancer 1978; 41: 56-63. https://doi.org/10.1002/10970142(197801)41:1<56::aid-cncr2820410110>3.0.co;2-2

[75] SIEGEL R, NAISHADHAM D, JEMAL A. Cancer statistics, 2012. CA Cancer J Clin 2012; 62: 10-29. https://doi. org/10.3322/caac.20138

[76] HSIEH MH, MENG MV, WALSH TJ, MATTHAY KK, BASKIN LS. Increasing incidence of neuroblastoma and potentially higher associated mortality of children from nonmetropolitan areas: analysis of the surveillance, epidemiology, and end results database. J Pediatr Hematol Oncol 2009; 31: 942-946. https://doi.org/10.1097/MPH.0b013e3181bcc809

[77] LONDON WB, CASTLEBERRY RP, MATTHAY KK, LOOK AT, SEEGER RC et al. Evidence for an age cutoff greater than 365 days for neuroblastoma risk group stratification in the Children's Oncology Group. J Clin Oncol 2005; 23: 64596465. https://doi.org/10.1200/JCO.2005.05.571

[78] SUZUKI M, KUSHNER BH, KRAMER K, BASU EM, ROBERTS SS et al. Treatment and outcome of adult-onset neuroblastoma. Int J Cancer 2018; 143: 1249-1258. https://doi. org/10.1002/ijc.31399

[79] BERTHOLD F, SPIX C, KAATSCH P, LAMPERT F. Incidence, Survival, and Treatment of Localized and Metastatic Neuroblastoma in Germany 1979-2015. Paediatr Drugs 2017; 19: 577-593. https://doi.org/10.1007/s40272-0170251-3

[80] MATTHAY KK, MARIS JM, SCHLEIERMACHER G, NAKAGAWARA A, MACKALL CL et al. Neuroblastoma. Nat Rev Dis Primers 2016; 2: 16078. https://doi.org/10.1002/ pbc. 24777
[81] MOSSÉ YP, DEYELL RJ, BERTHOLD F, NAGAKAWARA A, AMBROS PF et al. Neuroblastoma in older children, adolescents and young adults: a report from the International Neuroblastoma Risk Group project. Pediatr Blood Cancer 2014; 61: 627-635. https://doi.org/10.1002/pbc.24777

[82] DUAN K, DICKSON BC, MARRANO P, THORNER PS, CHUNG CT. Adult-onset neuroblastoma: Report of seven cases with molecular genetic characterization. Genes Chromosomes Cancer 2020; 59: 240-248. https://doi.org/10.1002/ gcc. 22826

[83] STUTTERHEIM J, GERRITSEN A, ZAPPEIJ-KANNEGIETER L, KLEIJN I, DEE R et al. PHOX2B is a novel and specific marker for minimal residual disease testing in neuroblastoma. J Clin Oncol 2008; 26: 5443-5449. https://doi. org/10.1200/JCO.2007.13.6531

[84] KRAMER K, GERALD WL, KUSHNER BH, LARSON SM, HAMEED $M$ et al. Disaloganglioside GD2 loss following monoclonal antibody therapy is rare in neuroblastoma. Med Pediatr Oncol 2001; 36: 194-196. https:// doi.org/10.1002/1096-911X(20010101)36:1<194::AIDMPO1046>3.0.CO;2-B

[85] YU AL, GILMAN AL, OZKAYNAK MF, LONDON WB, KREISSMAN SG et al. Anti-GD2 antibody with GM-CSF, interleukin-2, and isotretinoin for neuroblastoma. N Engl J Med 2010; 363: 1324-1334. https://doi.org/10.1056/NEJMoa0911123

[86] VOELLER J, SONDEL PM. Advances in Anti-GD2 Immunotherapy for Treatment of High-risk Neuroblastoma. J Pediatr Hematol Oncol 2019; 41: 163-169. https://doi.org/10.1097/ MPH.0000000000001369

[87] KUSHNER BH, KRAMER K, CHEUNG NK. Chronic neuroblastoma. Cancer 2002; 95: 1366-1375. https://doi. org/10.1002/cncr.10800 